\title{
A história do livro e da edição um observatório privilegiado do mundo mental dos homens do século XVIII ao século $X^{*}$
}

\author{
The history of the book and the edition \\ a privileged observatory of mankind's mental world in the XVIII to \\ the $X^{\text {th }}$ centuries $^{* *}$
}

\section{L'histoire du livre et de l'édition}

un observatoire privilégié de l'univers mental des hommes du XVIII' au XXes

\author{
JEAN-YVESMOLLIER \\ Centre d'Histoire Culturelle des Sociétés Contemporaines \\ Université de Versailles Saint-Quentin-en-Yvelines Universidade de Versailles \\ 47, Boulevard Vauban. 78047. Guyancourt Cedexrance \\ Saint-Quentin-en-Yvelines. France \\ jean-yves.mollier@uvsq.fr
}

RESUMO Esse artigo pretende associar a história do livro com a da edição, analisando-as no período compreendido entre o nascimento da edição, no final do século XVIII e início do século XIX, particularmente na França e Inglaterra. É ao abordar o universo mental dos homens dos quais se examina as práticas culturais que se constrói a história do livro, da edição e da leitura na época da impressão.

Palavras chave livro, leitura, edição

$\begin{array}{ll}\text { * } & \text { Texto recebido em: 10/05/2009. Aprovado em: 18/07/2009. } \\ \text { ** } & \text { Tradução de Clara Furtado Lins. }\end{array}$ 
ABSTRACT This article aims to link the history of the book with the history of printing, analyzing the period between the birth of publishing, in the late eighteenth and early nineteenth century, particularly in France and in the United Kingdom. Exploring the mental universe of men and their cultural practices that make possible to write a history of book publishing and reading at the time of printing.

Keyword book, reading, edition

Há diferentes maneiras de escrever a história da impressão e é perfeitamente legítimo se dedicar, por exemplo, ao estudo apenas das aparências físicas desse objeto a que chamamos de "livro". Esta abordagem nos leva a observar as transformações materiais dos suportes sobre os quais o homem começou a escrever, dos ossos de mamíferos e cascos de tartaruga até estelas de pedra da China antiga ${ }^{1}$ e tabletes de argila da Mesopotâmia. Em seguida, vieram os rolos de papiro do Egito dos faraós e os pergaminhos da Biblioteca de Alexandria, antes de aparecer, em torno dos séculos I e II da era cristã, a substituição do volume pelo códice, e dois mil anos mais tarde, do códice pela tela plana ou reader. ${ }^{2}$ Desde o trabalho de Donald McKenzie, sabemos que não lemos o mesmo texto, apesar da ilusão que nos fornece a aparência da carta, pois tudo muda dependendo da maneira como ela é impressa. ${ }^{3}$ Baseando-se nas idéias de Erwin Panofsky, sobre a perspectiva considerada como uma forma simbólica, ele dá mais atenção ao que chama de "a forma expressiva" de que se reveste o livro. Ele convida o leitor a interessar-se pela tipografia, pelo layout, pela ilustração, ou o que Roger Laufer chamou de "escritura", ou seja, a produção de sentidos, os significados relacionados à ínfima materialidade do livro. ${ }^{4}$

No entanto, sem esquecer a importante contribuição dessas reflexões para uma visão não idealizada da história da transmissão de idéias, nosso ponto de vista é diferente e consiste em associar a história do livro com a da edição, por isso a preferência em se deter no período compreendido entre o nascimento da edição, no final do século XVIII e início do século XIX, ${ }^{5}$ do que no final do século XX. É neste período relativamente curto da história

1 O templo de Confúcio, na cidade de Xi'an, na China, conserva uma das mais belas coleções de estelas gravadas do mundo.

2 Entre 2000-2001, o livro eletrônico foi inicialmente chamado e-book, desde 2006, o livro a tinta eletrônica comercializado no mundo é mais propriamente denominado de reader.

3 MCKENZIE, Donald F. Bibliography and the sociology of texts. London: British Library, 1986.

4 MCKENZIE, Donald F. Bibliography and the sociology of texts; MCKENZIE, Donald F. Le livre comme forme expressive. In: La bibliographie et la sociologie des textes. Paris: Editions du Cercle de la Librairie, 1991, p.26-54.

5 MOLLIER, Jean-Yves. Naissance de la figure de l'éditeur. In: LEGENDRE, Bertrand e ROBIN, Christian. (dir.) Figures de l'éditeur. Paris: Nouveau Monde éditions, 2005, p.13-29, e para uma visão mais restritiva: DURAND, Pascal e GLINOER, Anthony. Naissance de l'éditeur. Paris/Bruxelles: Les Impressions nouvelles, 2005. 
humana que se produziu a reforma da educação universal, o que levou à leitura em massa de textos produzidos em série, que se tratavam, na préhistória destes fenômenos, dos "livros azuis", que circularam nas planícies campesinas francesas antes da Revolução de 1789, ou do "livro de bolso", que aparece, na Inglaterra, em 1935, e que será em seguida imitado por todos os lados. Incluindo o aparecimento das coleções de livros destinados ao público em geral, que surgem em grande número, em meados do século XIX, tanto na França, quanto na Grã-Bretanha, ou na Alemanha, e que precedem as "dime nove/s"6 americanas e os romances, inicialmente ao custo de quatro, depois três, dois e, finalmente, a um centavo francês, ${ }^{7}$ obtemos um material suficientemente abundante para permitir uma visão da evolução das práticas culturais. Trabalhando nesta área há mais de vinte e cinco anos, primeiramente numa perspectiva nacional ${ }^{8}$ e, depois, cada vez mais internacional e comparativa, ${ }^{9}$ queremos também situar esta abordagem na perspectiva antropológica aberta na França, por Lucien Febvre e os fundadores da revista Les Annales. ${ }^{10}$

Sem voltar aos debates que marcaram o final dos anos 1960 e início da década seguinte, e que viram se opor violentamente Michel de Certeau, Dominique Julia e Jacques Revel a Robert Mandrou ${ }^{11}$ - um dos mais talentosos sucessores de Lucien Febvre e aquele que havia retomado o conceito de "ferramenta mental"12 para o tornar um conceito comum aos historiadores ${ }^{13}$ -, vamos lidar com o conceito de "cultura popular" - o pomo da discórdia destes anos pós-60 - à luz de trabalhos mais recentes e menos polêmicos. Depois de Jean-François Botrel, um dos pais do estudo da "literatura de cordel", ${ }^{14}$ que havia iniciado Pio Baroja na Espanha, ${ }^{15}$ nós mesmos trabalha-

6 NT: Novelas de 1 centavo.

7 O franco germinal em uso no século XIX valia vinte sous e, teoricamente, cem centavos, mas a moeda de cinquenta centavos (um sou) era a menor unidade monetária em circulação por volta de 1900. As contas populares contavam em sous e os aristocratas en louis (luizes), um louis de ouro valia vinte francos ou 90 euros de hoje em dia. É necessário ainda saber que, em 1900, a reivindicação de um trabalhador parisiense era obter um "thune" por dia, ou seja cinco francos, para satisfazer suas necessidades e se beneficiar de um pouco de sobra para seu lazer.

8 MOLLIER, J.Y. L'argent et les lettres. Histoire du capitalisme d'édition. Paris: Fayard, 1988, e MOLLIER, J.Y. Edition, presse et pouvoir en France au XXe siècle. Paris: Fayard, 2008, para um panorama desses trabalhos.

9 MOLLIER, J.Y. A continent of texts: Europe 1800-1890. ELIOT, Simon e ROSE, Jonathan. (eds.) A companion to history of the book. Oxford/New York: Blackwell Publishing Ltd, 2007, capítulo 22. Esta coletânea de 599 páginas é considerado o livro mais completo sobre o assunto.

10 FEBVRE, Lucien. Combats pour l'histoire. Paris: Armand Colin, 1992. O autor reagrupa os textos essenciais sobre o tema.

11 CERTEAU, M. de ; JULIA, D. e REVEL, J. La beauté du mort. Le concept de 'culture populaire', Politique aujourd'hui, décembre 1970. Republicada em CERTEAU, M. de. La culture au pluriel. Paris: UGE, , 1974, p.55-94.

12 NT: No original, "outillage mental".

13 Ver FEBVRE, Lucien. Le problème de l'incroyance au XVle siècle : la religion de Rabelais. Paris: Albin Michel, 1942 para o aparecimento da expressão e MANDROU, Robert. Introduction à la France moderne 1500-1640. Essai de psychologie historique. Paris: Albin Michel, 1961, para o desenvolvimento do conceito.

14 BOTREL, J.F. La confrérie des aveugles de Madrid et la vente des imprimés: du monopole à la liberté du commerce (1581-1836). Mélanges de la Casa de Velazquez, Madrid, t.IX, p. 417-482, 1973 ; e BOTREL, J.F. Aspects de la littérature de colportage sous la Restauration: I'infralittérature en Espagne aux XIX' et XXe siècles. Grenoble: PUG, 1977.

15 BAROJA, Pio. Carteles de feria y literatura de cordel. Revista de informacion medico-terapeutica, t.XXII, fascicules n.21-22, p.1024-1033, 1947 
mos muito com esta "littérature du ruisseau"16 e com a biblioteca de mesmo nome, que floresceu na França durante a Belle Epoque. ${ }^{17}$ Destinados aos "comedores de papel" recém-desembarcados nas cidades ou recentemente alfabetizados, estes textos com aparência bastante cru, mal conservados em bibliotecas, não são muito diferentes da littérature de colportage ${ }^{18}$ que hoje em dia encontramos na Bahia e no nordeste do Brasil, ou na Índia, que relata as lendárias glória dos bandidos dos grandes caminhos e no mundo árabe-muçulmano, que vê as multidões preferirem as lojas das calçadas às livrarias. ${ }^{19}$ Quer se aprecie ou não o humor muitas vezes rude, escatológico, que emana desses textos ou a controvérsia política torpe que os atravessa, não se pode ignorar essas formas de consumo popular de cultura. É então, ao tentar desenhar os contornos do universo mental dos homens dos quais se examina as práticas culturais que deve se circunscrever, em nossa opinião, a história do livro, da edição e da leitura na época da impressão, se queremos que ela saia da erudição ou da especialização na qual ela havia acreditado que podia se fechar em sua origem.

\section{O nascimento do editor, um momento chave da conquista de novos públicos leitores}

Há muito tempo hesitamos em lançar luz na figura do editor, mas a indiferenciação entre as profissões em torno do livro, anteriormente unidos sob o termo genérico de "livreiros", não ajudou a vê-lo claramente. Se, em inglês, diferenciamos o publisher do editor e do bookseller, ${ }^{20}$ é a Stationers' Company que reagrupou, nos séculos XVII e XVIII, os impressores e os editores. Este termo surgiu do latim e designava muito claramente mais o bibliotecário - aquele que ficava literalmente de pé no scriptorium da Idade Média -, do que o futuro dono da obra colocada em circulação. É então, no momento do crescimento dos leitores, e logo da inflação de demanda, ela mesmo fruto da revolução industrial e da urbanização da Europa, que obrigava os "livreiros" a se especializarem, que algo decisivo aconteceu no Reino Unido, na Alemanha e na França, antes de se espalhar pelo mundo inteiro. Londres tornou-se a capital do livro antes de 1800, relegando à Leipzig o papel de organizar grandes feiras anuais onde se encontravam importantes comissionários, nossos difusores. A capital do império britânico

16 NT: "Littérature du ruisseau", ou de "riacho" - usada aqui como pejorativo -, refere-se à literatura menor, vendida nas ruas, na forma de folhetins, impressos, cordel, etc.

17 MOLLIER, J.Y. Le camelot et la rue. Politique et démocratie au tournant des XIX et XXe siècles. Paris: Fayard, 2004. Tradução em português saiu pela Edusp, São Paulo, 2009.

18 NT: O termo se refere a todo tipo de literatura menor, referida na nota 16, que era vendida nas ruas por ambulantes.

19 Para numerosos exemplos contemporâneos: MOLLIER, J.Y. Le camelot et la rue.

20 NT: Como no francês, as duas primeiras categorias são de difícil distinção no português, a terceira se refere ao vendedor ou comerciante de livros. A grosso modo, editor se refere tanto ao dono de uma editora, quanto ao responsável pela preparação editorial dos livros. 
concentrava o grosso dos profissionais do livro, antes que a província, a Escócia e depois a Irlanda despertassem e tentassem roubar da Inglaterra uma parte de sua liderança. ${ }^{21} \mathrm{Na}$ França, onde também existiam algumas formas de associação e de exploração conjunta do privilégio de edição concedido pelo poder real, é precisamente a quase-asfixia do sistema corporativo, após 1760, que levou ao aparecimento da nova figura do editor. ${ }^{22}$ Charles-Joseph Panckoucke foi seu arquétipo, ele que tinha adquirido de seu colega, André François Le Breton, o privilégio e as placas de bronze da Enciclopédia, esta enorme máquina em torno da qual se desenvolveu uma parte essencial da mensagem modernista do lluminismo.

Sabemos que esta coleção de 17 volumes in-folio, não incluindo outros 11 reservados às pranchas, nem os 5 suplementos e os quadros, trouxe uma quantidade enorme de dinheiro aos livreiros associados que tiveram a idéia de traduzir e depois adaptar a Cyclopaedia, de Chambers, antes de deixar Diderot e d'Alembert alterarem radicalmente o projeto, ${ }^{23}$ mas é mais interessante ainda analisar o papel do comprador da edição - Charles-Joseph Panckoucke. Os lucros resultantes da empresa, cerca de 2, 5 milhões dos 4 milhões de vendas gerados pela primeira edição, ${ }^{24}$ deixaram entrever um ganho importante para o futuro. Mas, se essa expectativa era possível, era ao mesmo tempo irrealista, uma vez que os quatro iniciadores da operação comercial consideravam que ela já havia gerado tudo o que era possível de se esperar dentro das condições de mercado existentes quando eles se retiraram da empresa. Foi então que, invertendo a lógica inerente ao negócio dos livros, a de uma resposta às demandas da sociedade, e colocando-a sob a tutela da oferta futura apresentada pelos editores, que Panckoucke efetuou um passo decisivo para o setor livreiro e realmente forçou-o a mudar. Para tornar seu investimento futuro rentável, era necessário fazer surgir do nada o público ainda ignorado e, para esse fim, era necessário provocar uma rápida queda dos preços de venda dos volumes. Ao realocar a impressão em Neuchâtel, então um principado prussiano qualquer localizado na atual Suíça, ao comprar todos os jornais e gazetas disponíveis a fim de aumentar a publicidade a favor de suas coleções e ao utilizar todos os métodos imagináveis, notadamente a difusão de seus livros em toda a Europa, para aumentar o número de seus clientes, o homem não foi, como diz sua biografia, "o último grande editor do Antigo

21 RAVEN, James. British Publishing and Bookselling: constraints and developments. In: MICHON, J. e MOLLIER, J.Y. (dir.) Les mutations du livre et de l'édition dans le monde du XVIII' siècle à l'an 2000. Québec/Paris: Presses de I'Université Laval/L'Harmattan, 2001, p.19-30.

22 A Lettre sur le commerce de la librairie (Carta sobre o comércio da livraria), 1763, de Denis Diderot, é testemunho privilegiado dessa situação de bloqueio da livraria francesa e um dos protagonistas de sua renovação.

23 DARNTON, Robert. L'Aventure de l'Encyclopédie. Paris: Librairie Académique Perrin, 1981.

24 DULAC, Georges. L'Encyclopédie. In: FOUCHE, P.; PECHOIN, D. e SCHUWER, P. (dir.) Dictionnaire encyclopédique du livre. Paris: Ed. du Cercle de la Librairie, 2002-2009, 3 vol., t.2, p.68-69. 
Regime", ${ }^{25}$ mas, pelo contrário, foi o primeiro editor dos novos tempos, no sentido pleno do termo. ${ }^{26}$

Graças aos seus esforços e ao dinamismo daqueles que o imitaram ou tentaram o enganar fazendo edições piratas da Enciclopédia, mais de 24.000 coleções completas circularam na Europa antes da Revolução Francesa e muitas se destinaram à América, contribuindo para a difusão de seu conteúdo e popularizando os nomes de Voltaire e de Jean-Jacques Rousseau, para muito além de seu país de origem. ${ }^{27} \mathrm{Na}$ seqüência deste sucesso, Charles-Joseph Panckoucke decidiu, em 1782, lançar outra série de volumes destinados a reunir a quintessência do conhecimento útil ao homem honesto, a Enciclopédia metódica. Planejada com uma ordem temática, e não mais alfabética, ela sofrerá seguidos atrasos devido à queda do Antigo Regime e a sua substituição por regimes instáveis, que modificavam constantemente a legislação, o que irá atrasar a sua conclusão, ocorrida apenas cinqüenta anos após seu lançamento. Se esquecermos este aspecto puramente conjuntural de sua história, a Enciclopédia metódica constituiu uma espécie de exemplo do advento do novo homem que representava o editor. Foi elaborada pelo próprio livreiro, que a partir de então reunia os autores que ele recruta, paga e comanda, seja em sua pocilga, seja em estábulos para falar a língua esportes hípicos. Esse processo ilustra o nascimento de um homem duplo, à cavalo entre dois mundos, o da mercadoria e o do espírito. Mais que simplesmente um negociante hábil, empreendedor e esperto, como tinham sido Briasson, David, Durand e Breton, era intelectualmente capaz de se colocar à frente dos homens de letras, de com eles compartilhar opiniões e de se parecer como seus iguais.

Após a queda da monarquia e uma vez passadas as guerras da revolução e do império, muitas editoras comparáveis ao modelo iniciado por Charles Joseph Panckoucke baixaram a cortina sobre a livraria romântica. Entre eles, destacaremos Pierre-François, chamado Camille Ladvocat aquele que Balzac colocou próximo ao seu personagem, Dauriat, o editor do Palais-Royal, para onde foi Lucien Rubempré quando chegou a Paris, na segunda parte de Ilusões perdidas -, ou ainda Urbain Canel, Léon Curmer, Charles Gosselin, Louis Mame, Eugène Renduel e Edmond Werdet, que foram os intermediários de Balzac, Victor Hugo e Lamartine junto ao públi$\mathrm{co}^{28}$ Homens novos, sem laços com o meio da livraria tradicional, cheios de energia como os heróis de Stendhal, e desesperados para ter sucesso, eles tinham que inovar constantemente para imprimirem seus nomes na

25 TUCOO-CHALA, Suzanne. Charles-Joseph Panckoucke et la Librairie française, 1736-1758. Pau/Paris: Marrimpouey Jeune/Jean Touzot, 1977, p.253.

26 MOLLIER, J.Y. L'argent et les lettres, p.24 ; e MOLLIER, Jean-Yves. Naissance de la figure de l'éditeur, p.17.

27 DARNTON, Robert. L'Aventure de l'Encyclopédie.

28 FELKAY, Nicole. Balzac et ses éditeurs. 1822-1837. Essai sur la librairie romantique. Paris: Promodis/Editions du Cercle de la Librairie, 1987. 
capa dos livros e manterem-se no centro da agitação parisiense. Entre eles destaca-se um profissional, Gervais Charpentier, o inventor do formato que leva o seu nome, "o grande in-18 'inglês' disse Jesus", ou seja, o criador de uma contra-ofensiva destinada a salvar a edição francesa ameaçada de morte pela concorrência estrangeira. ${ }^{29}$ Enquanto os impressores belgas tinham substituído seus colegas franceses na divulgação de sua produção na Europa, porque eles produziam livros a um preço muito mais baixo que o deles, o editor parisiense decidiu por sua vez competir com eles lançando, em 1838, a "Coleção Charpentier", constituída de pequenos volumes compactos de $18,5 \times 11,5 \mathrm{~cm}$, vendidos a $3 \mathrm{~F} 50$ (15 a $16 €$ ), três a quatro vezes mais barato que os volumes chamados "de gabinete de leitura", os in-8 clássicos.

Logo ultrapassadas pelos editores ainda mais ousados, tal como Michel Lévy, que, em 1846, lança a coleção das Obras Completas, de Alexandre Dumas pai, a dois francos; ${ }^{30}$ Gervais Charpentier constitui, entretanto, um dos modelos, juntamente com Camille Ladvocat, o famoso Dauriat, de Ilusões perdidas, que Balzac pintou, em 1837, como "o padisha da livraria", ou seja, o verdadeiro deus ex machina do campo literário da época. Com a arrogância que o dinheiro e o poder fornecem, o personagem explicava calmamente aos seus visitantes:

Vou precisar em breve de uma administração para reger o depósito de manuscritos, um escritório de leitura para examiná-los; haverá reuniões para votar seu mérito, com jetons de presença e um secretário permanente para me apresentar os relatórios. ${ }^{31}$

Isto não poderia antecipar melhor os comitês de leitura do século XX, aqueles da Editions Gallimard, do período entre-guerras, parecendo se encaixara nesse quadro apenas imaginado cento e cinqüenta anos antes. Também atingido pelo surgimento na cena pública desses "altos barões do feudalismo industrial", o jornalista Elias Regnault deveria fazer um retrato do grupo no capítulo "editor" na publicação coletiva de sucesso, intitulada Les Français peints par eux-mêmes, ${ }^{32}$ publicada nesse mesmo momento. Com estes dois exemplos literários, pode-se dizer que um tipo social nasceu, anteriormente desconhecido, ignorado pelos juristas e legisladores, já que o decreto napoleônico, de 5 de fevereiro de 1810, que deveria reger pelos próximos sessenta anos os ofícios do livro na França, conhecia apenas

29 OLIVERO, Isabelle. L'invention de la collection. Paris: IMEC Editions, 1999

30 MOLLIER, J.Y. Michel et Calmann Lévy ou la naissance de l'édition moderne. 1836-1891. Paris: Calmann-Lévy, 1984.

31 BALZAC. Illusions perdues. In: La Comédie humaine. Paris: Gallimard, 1966, t.IV, p.701. (Bibliothèque de la Pléiade)

32 REGNAULT, Elias. Editeur. Les Français peints par eux-mêmes. Paris: Curmer, 1839-1842, 8 vol. Reeditado em Paris, 2004, t.2, p.943-944. (Coleção La Découverte "Omnibus"). 
duas categorias: impressores e livreiros, ${ }^{33}$ mas acenou para um futuro brilhante, pois é apenas no final do século XX que começamos a antever seu declínio. ${ }^{34}$

Longe de se limitar à França, o fenômeno foi universal, mas antes de passar para o restante do continente, começou a brilhar no Reino Unido, devido à concentração das profissões do livro em Londres, no distrito da catedral de Saint Paul. Foi ali que se organizaram, no final do século XVIII, os Longman, Murray, Rivington e Robinson, a quem se uniram, no início do século XIX, os McMillan, Routledge e Smith. ${ }^{35}$ Forçados a alterar suas práticas pela abolição, em 1774, do regime de propriedade perpétua dos direitos do autor, esses novos editores iriam, eles também, se instalar sobre os escombros das empresas antigas e fizeram nascer, no seio da Stationers' Company, esses novos editores que irão dominar o sistema e construir os impérios, alguns dos quais perduram até hoje. John II Murray, que se tornou editor de guias de referência de viagem, em breve será imitado pelo alemão Karl Baedeker e pelo francês Adolphe Joanne, mas ele lhes imporá a cor vermelha como emblema das capas dos guias turísticos e esta é uma vitória que muito poucos editores poderiam honrar-se posteriormente. ${ }^{36}$ Sem dúvida convém associar a eles, mas em um outro gênero, o alemão Friedrich Arnold Brockhaus, que não foi o inventor, mas o comprador notificado do Konversationslexikon, o antepassado dos dicionários portáteis que circulariam na Europa e, em seguida, no mundo inteiro, a partir do início do século XIX ${ }^{37}$ Como Murray e como Panckoucke, Brockhaus figura nesta linha de editores autênticos, que deveriam modificar profundamente as relações do homem com o livro, porque ele concebia as produções que colocava em seus catálogos como bens de grande circulação, para não dizer de grande consumo. Ao mesmo tempo, convencidos de que esses livros só podiam contribuir para o desenvolvimento da sociedade em que viviam, eles não separaram a produção em massa - pelo menos como tendência, já que as grandes impressões só começariam mais tarde - do enriquecimento espiritual dos leitores e, nisto, eles eram sintomas de uma época que acreditava no progresso indefinido das sociedades.

\section{Um continente de textos}

O século XIX não inventou o fenômeno das coleções, desde que Roger Chartier contou uma trintena para o fim do século XVII e todo o século XVIII, 38

33 MOLLIER, J.Y. La police de la librairie. 1810-1881. In: SOREL, P. e LEBLANC, F. (dir.) Histoire de la librairie française. Paris, 2008, p.16-26.

34 SCHIFFRIN, André. L'édition sans éditeurs. Paris: La Fabrique, 1999.

35 RAVEN, James. British Publishing and Bookselling: constraints and developments.

36 GUILCHER, Goulven. Les guides de chemins de fer: pratiques anglaises et françaises. MOUREAU, F. e PALINO, M. N. (dir.) Ecritures des chemins de fer. Paris: Klincksieck, 1992, p.22-36.

37 BARBIER, Frédéric. L'empire du livre. Paris: Ed. du Cerf, 1995, p.326-328.

38 CHARTIER, Roger L'ordre des livres. Lecteurs, auteurs, bibliothèques en Europe entre XIVe et XVIII' siècle. Aix-enProvence: Alinéa, 1992, p.74-75. 
mas estas explodiram realmente depois de 1830. Tratava-se de centenas de "bibliotecas", como as chamamos na maioria das vezes, ou de "coleções", como se começa a dizer, que aparecem na França, no Reino Unido ou na Alemanha, antes de se propagarem pela Espanha, por Portugal e pela América Latina. ${ }^{39}$ Conhecemos o sucesso das "Railway libraries", ${ }^{40}$ dos editores Bentley, Mac Intyre ou Routletdge, também conhecidos como yellow-backs, ${ }^{41}$ bem como o da "Bibliotèque des chemins de fer", de Louis Hachette, famosa pela sua quarta capa plana, onde havia desenhada uma locomotiva inglesa cuspindo um jato potente de vapor, e dividida em oito séries, cada uma com suas cores específicas, do rosa claro para as crianças ao vermelho dos guias Joanne. ${ }^{42}$ Cita-se muito frequentemente a "Universal Bibliothek", ${ }^{43}$ de Anton Philip Reclam, lançada em 1867, a um preço muito acessível (20 pfennigs, ou cerca de um euro atual) e que publicará, em 1910, o quinto-milionésimo título de seu catálogo. ${ }^{44}$ Se acrescentarmos, como fez Frédéric Barbier, que, em 1912, a firma Reclam instalará em estações e edifícios públicos, "a partir de Erfurt, os primeiros distribuidores automáticos de livros, dos quais [ela] obteve exclusividade" ${ }^{45}$ entende-se que esta é a coleção que levou mais longe o princípio da lógica industrial e da cultura de massa, expressas nas primeiras antecipações dos anos 1830.

Observando o material publicitário distribuído pelos editores na origem destas iniciativas, percebe-se suas hesitações, suas tentativas e seus erros, e pode-se até mesmo penetrar em parte dos seus imaginários. Assim, Gervais Charpentier pode ter sido o pai dessa pequena revolução do livro barato que abalou a França a partir de 1838, mas ele mesmo não mediu todos os efeitos de sua iniciativa. No artigo de sua autoria publicado no Journal des Débates, em novembro de 1841, explicava as intenções que o nortearam desde a criação da série de livros que emprestam seu nome. O editor se orgulhava de, nessa coleção, reunir apenas a elite da literatura universal e de trabalhar para ajudar "o homem de gosto" a compor "uma biblioteca realmente escolhida, que reunia, como os anéis de uma mesma cadeia, as produções mais notáveis do espírito humano" ${ }^{46}$ Estava aí um projeto que homenageava aqueles que tinham desenvolvido a idéia, mas ela não tinha nada a ver com a opinião daqueles, como Michel Lévy, o antepassado reivindicado por Gaston Gallimard, que extraíam de suas origens populares o desejo ambicioso de criar nos homens de seu tempo uma necessidade de

\footnotetext{
39 Um ateliê da Biblioteca Nacional da França foi consagrado ao tema das coleções em 2002. As atas saíram pelas Editions du Céfal, em 2009 ou 2010.

40 NT: Coleções de livros das estradas de ferro.

41 OLIVERO, Isabelle. L'invention de la collection, p.72-75. NT: Capas amarelas.

42 MOLLIER, J.Y. Louis Hachette (1800-1864). Le fondateur d'un empire. Paris: Fayard, 1999, p.329-342.

43 NT: Biblioteca Universal.

44 BARBIER, Frédéric. L'empire du livre, p.92-96.

45 BARBIER, Frédéric. L'empire du livre, p.96.

46 Journal des Débats, 5 novembre 1841. Apud: OLIVERO, Isabelle. L'invention de la collection, p.57.
} 
ler tão poderosa como a de beber ou comer. ${ }^{47}$ Ele já havia se manifestado de forma diferente, em fins de 1855, escrevendo no prospecto distribuído nas avenidas e destinado a fazer conhecido sua recente "Coleção Michel Lévy", a um franco o volume (4, 5 euros), que, segundo ele, foi "chamada para inaugurar, em relação aos preços, uma nova fase no comércio da livraria francesa". ${ }^{48}$ Ele havia inclusive previsto, em 1846, lançando as CEuvres completes, ${ }^{49}$ de Dumas, no formato "Charpentier", que "o reinado de folhetins cosidos em volumes pela dona de casa [havia] passado". ${ }^{50} \mathrm{E}$, se isto não era exato, uma vez que esta prática só desapareceu completamente depois de 1914, ${ }^{51}$ no entanto, pelo menos a afirmação advogava em favor da leitura para todos, o que era essencial.

Para estes homens que tinham testemunhado o início desta "silenciosa revolução cultural", ${ }^{52}$ que iria ocorrer no final do século XIX, quando as últimas conseqüências da alfabetização em massa se fizeram sentir - mais de 30 milhões de leitores de jornais por dia para 40 milhões de habitantes na França em 1900 -, a reforma da educação universal, colocada em prática em 1833, deveria libertar o homem de sua condição e elevá-lo acima dela. Esta concepção otimista havia sido criação dos Convencionais que, em 1792-1793, tinham estabelecido as orientações gerais do programa que imprimiram aos revolucionários. Mas Napoleão I não a entendeu assim, e nada de importante havia sido feito quando, no final da Restauração, em 1828, o debate foi relançado por uma associação, a Sociedade para a Instrução Elementar, a qual deu o impulso decisivo à reforma. Ainda que atrasada pelo curso de acontecimentos políticos, a primeira lei que impôs a todas as comunas de mais de quinhentos habitantes a manutenção de uma escola primária para rapazes e a educação gratuita para crianças carentes foi aprovada a 28 de junho de 1833. O ministro, François Guizot, foi o iniciador e, se ele foi criticado mais tarde, sua obra continuou, para atingir, por volta de 1880, a erradicação definitiva do analfabetismo. Ele contribuiu para distribuir aos felizes beneficiários desta legislação quase dois milhões de livros de leitura ou de cálculo, ${ }^{53}$ e, assim, ele e seus colegas desencadearam um tsunami que nada mais poderia parar.

Houve pouca polêmica política ou de mídia a propósito das reformas que ninguém ousou realmente desafiar, mas o debate deveria se deslocar e

47 MOLLIER, J.Y. Michel et Calmann Lévy ou la naissance de l'édition moderne, p.426.

48 Collection Michel Lévy, choix des meilleurs ouvrages contemporains, octobre 1855. Coleção pessoal do autor.

49 NT: Obras completas.

50 CEuvres complètes d'Alexandre Dumas format de la Bibliothèque Charpentier à 2 francs le volume, 1846. Coleção pessoal do autor.

51 Os últimos exemplares de folhetins cosidos com costura, encontrados por René Guise, tinham sido produzidos antes de 1945. Comunicação de René Guise no seminário de J.Y. Mollier, em 1993.

52 Nós desenvolvemos esta ideia em: MOLLIER, J.Y. Le manuel scolaire et la bibliothèque du peuple. Romantisme, n.80, 1993. Retomada em: MOLLIER, J.Y. A leitura e seu publico no mundo contemporâneo. Ensaios sobre História Cultural. Belo Horizonte: Autêntica, 2008, p.61-81.

53 MOLLIER, J.Y. Louis Hachette (1800-1864), p.162-170. 
se focalizar quase ao mesmo tempo sobre as conseqüências do nascimento de um novo gênero literário, o romance de folhetim. Inicialmente, o folhetim era apenas uma categoria que apareceu na imprensa entre 1799 e 1800 e do qual distinguimos duas variantes, o "folhetim literário", ou seja, a crítica das novidades, e o "folhetim dramático", o dos espetáculos. Foi a partir dos anos 1832-1835, que alguns jornais começaram a publicar nesta categoria ou na de "variedades" os romances que, dessa maneira, eram publicados na íntegra, mas numa seqüência de fragmentos de tamanho reduzido..$^{54} \mathrm{O}$ procedimento já era utilizado pelas grandes revistas políticas e literárias, do tipo Revue des Deux Mondes e Revue de Paris, que apareceram em 1829. Mas, enquanto estas estavam reservadas ao público culto, pouco numeroso e educado, amantes das Belles Lettres, aquele do cotidiano era, por definição, muito menos socialmente homogêneo, já que os cafés e os gabinetes de leitura colocavam a imprensa à disposição de seus clientes. Foi, então, em 1836, que o jornal para todos - ou quase, porque as tiragens eram muito modestas antes de 1863, quando nasceu a imprensa popular a um centavo - começou a incluir o romance como um de seus argumentos de venda favoritos. Quando Emile de Girardin lançou La Presse e Dutacq, Le Siècle, começou "a querela do romance-folhetim", que ecoaria até atingir o Parlamento. ${ }^{55}$

Ela deveria levar a um voto particularmente caricatural, aquele da emenda Riancey que, em julho de 1850, criou um imposto específico aos jornais que publicavam folhetins em suas colunas. ${ }^{56}$ Logo anulada, a ação discriminatória foi o culminar de um violento debate entre aqueles que consideravam a leitura de romances-folhetins uma ameaça para a sociedade e seus opositores: de um lado, os editores e proprietários da imprensa; de outro, os escritores populares, que, ao contrário, viam ser uma oportunidade. Augustin Sainte-Beuve emerge nesta batalha com a publicação, na Revue des Deux Mondes, de $1^{\circ}$. de setembro de 1839, de seu famoso artigo sobre "a literatura industrial", no qual criticou a mudança e a substituição das Belles Lettres pela literatura de mercado. Ele denunciou também a responsabilidade de Balzac e Dumas nessa mudança das sensibilidades e se associou, de certa maneira, com aqueles que, na Igreja Católica, juravam ao inferno ou ao Index librorum prohibitorum essa prosa julgada insana e perniciosa. ${ }^{57}$ Muito cedo, se apontou o dedo contra os "negros", suspeitos de ajudar alguns "folhetinistas" a preparar sua "cozinha" literária e um jornalista conhecerá seu instante de fama com a publicação de um panfleto

54 THERENTY, Marie-Eve. La littérature au quotidien. Paris: Seuil, 2007 ; e THERENTY, Marie-Eve e VAILLANT, Allain. 1836. L'an I de l'ère médiatique. Paris: Nouveau Monde éditions, 2001.

55 Queffélec-Dumasy, Lise. La querelle du roman-feuilleton. Littérature, presse et politique, un débat précurseur. Grenoble: ELLUG, 1999

56 MOLLIER, J.Y. A leitura e seu publico no mundo contemporâneo, p.99.

57 ARTIAGA, Loïc. Des torrents de papier. Catholicisme et lectures populaires au XIXe siècle. Limoges: PULIM, 2007. 
intitulado Fabrique de romans. Maison Alexandre Dumas et compagnie. ${ }^{58}$ Ele permitiu que o público tomasse consciência da mudança que vinha se produzindo na literatura, uma vez que o número de franceses que sabiam ler havia crescido e ele ressaltava, à sua própria maneira, os vínculos que uniam a reforma universal da educação, a entrada do país na era da mídia e o advento próximo ou provável de uma cultura em massa, ela mesma considerada um produto do aparecimento das primeiras indústrias culturais, em primeiro lugar, da edição popular.

\section{Quem tem medo da cultura popular?}

O surgimento dos primeiros "livros azuis", em Troyes, no século XVII, não parece ter perturbado as autoridades, e foi só quando o comércio de rua se tornou um problema político, entre 1848 e 1849, que se passa a se interessar por um gênero que parecia popular por destino e, talvez, mesmo por essência. Charles Nisard, o secretário da comissão encarregada de reprimir e controlar essa literatura e aqueles que a difundiam, foi seu primeiro historiador e publicou uma Histoire des livres populaires ou de la littérature de colportage ${ }^{59}$ que contribuiu fortemente para obscurecer suas origens. Quando Robert Mandrou utilizou este material para tentar se aproximar da cultura popular dos homens dos séculos XVI e XVII, foi também vítima de um erro de perspectiva, o que não deixou de colocar em evidência aqueles que, após 1968, quiseram enterrar a história das mentalidades e pegar o lugar dos mais velhos na "grande perseguição", conhecida em latim como o cursus honorum. Michel de Certeau e os seus jovens amigos participaram alegremente da cura desse mal e o artigo que publicaram, voluntariamente intitulado $A$ beleza da morte, pode ser considerado uma ruína acadêmica destinada ao abate do "mandarim" que prevalecia na revista Les Annales. ${ }^{60}$ Certamente, é difícil sustentar hoje em dia que é possível encontrar nos livros azuis traços das mentalidades populares, mas o debate ainda não terminou devido à multidão de impressos de grande circulação existentes na Europa naquela época.

Roger Chartier, sem participar diretamente dessa polêmica, ajudou a iluminar o contexto editorial da produção e depois da distribuição destes pequenos livros impressos em papel de má qualidade e com conteúdo tão heterogêneo que perturbou os primeiros pesquisadores que os tinham

58 MOLLIER, J.Y. A leitura e seu publico no mundo contemporâneo, p.88. NT: Fábrica de romances. Casa de Alexandre Dumas e companhia.

59 NISARD, Charles. Histoire des livres populaires ou de la littérature de colportage. Paris: Dentu, 1864. Foi reeditada em 1968 por Maisonneuve et Larose. NT: História dos livros populares ou da literatura de rua.

60 Ver HEBRARD, Jean. Peut-on faire une histoire des pratiques populaires de lecture à l'époque moderne ? Les 'nouveaux lecteurs' revisités. Matériaux pour une histoire de la lecture et de ses institutions, n.17, p.105-140, 2005, para uma reconstituição minuciosa do contexto desse embate que deixou cicatrizes no corpo da vítima. 
analisado. ${ }^{61}$ Ao mostrar que se tratava de reciclagem e junção de produtos já impressos que haviam deixado de agradar àqueles para quem haviam sido concebidos, ele permitiu uma abordagem mais refinada deste material tão freqüentemente fantasiado, cujos artesãos tinham procurado, desde o início, angariar um lucro rápido com os mesmos. ${ }^{62}$ Seria necessário, então, focar nas múltiplas e diferentes apropriações dos mesmos textos pelos seus sucessivos leitores se quiséssemos compreender as razões do seu sucesso e não procurar neles as fontes de uma hipotética cultura popular miraculosamente conservada. Isso não resolve completamente a questão do sucesso eventual destes pequenos livros azuis que podemos também tentar explicar pelas expectativas dos leitores, ou seja, por uma aproximação com a sua psicologia, seus gostos, sua educação, ou seja, de todos os elementos díspares que compõem o que os antropólogos chamam de cultura. De toda maneira, a multiplicação das "coleções-panteão", após 1830, e das "coleções de prospecção", após essa mesma data, ${ }^{63}$ levou as instituições, como a igreja, a escola, o parlamento, o Estado, a darem seus pareceres sobre os temas sobre os quais se referiam as revistas literárias. Ao mesmo tempo, tentaram refrear o desejo das pessoas em ler estas produções e, por esta via, entraram na área do lazer que as elites há muito consideravam como um campo que lhes era exclusivo. ${ }^{64}$

Embora fosse relativamente fácil ao poder reacionário e ditatorial de Luís Napoleão Bonaparte, a partir de 1849, quebrar o ritmo do "romance a quatro centavos" e daquele "de rua", o mesmo não podia impedir a irradiação das coleções populares, nem mesmo parar aquela dos almanaques, ainda muito procurados no campo francês até $1914 .{ }^{65}$ Após a queda do Segundo Império e da proclamação da Terceira República, em 1870, a prodigiosa ascensão da imprensa popular de um centavo - que passou em trinta anos de um a quase dez milhões de compradores diários - levaria as elites a temer o nascimento de uma cultura em massa cujos fundamentos Ihes escapavam. Como a legislação em matéria de distribuição de jornais havia evoluído em paralelo com esse aumento constante de leitores e os vendedores ambulantes haviam sido autorizados, na província, em 1863, e em Paris, em 1868, as vendas por assinatura diminuíram drasticamente. ${ }^{66}$ Desde então, a apresentação da informação e o foco colocado sobre as

61 BOLLEME, Geneviève. La bibliothèque bleue. La littérature populaire en France du XVIIe au XVIII siècle. Paris: Gallimard-Julliard, 1971. Coleção Archives; e DELCOURT, Thierry e PARINET, Elisabeth. (dir.) La bibliothèque bleue et les littératures de colportage. Paris/Troyes, Ecole des Chartes/La maison du Boulanger, 2000.

62 CHARTIER, Roger. Stratégies éditoriales et lectures populaires. 1530-1660. In: lectures et lecteurs dans la France d'Ancien Régime. Paris: Seuil, 1987, p.87-124.

63 Mollier, J.Y. Les collections littéraires au XIXe siècle. In: Livres de poche et collections. (no prelo).

64 CORBIN, Alain. (dir.) L'avènement des loisirs, 1850-1960. Paris: Aubier, 1995

65 LÜSEBRINK, Hans-Jürgen; MIX, York-Gothart; MOLLIER, Jean-Yves e SOREL, Patricia. (dir.) Les lectures du peuple en Europe et dans les Amériques (XVIle-XXe siècle). Bruxelles: Complexe, 2003.

66 MOLLIER, J.Y. Le camelot et la rue. Politique et démocratie au tournant des XIXe et XXe siècles. Paris: Fayard, 2004. 
notícias sensacionalistas contavam tanto, se não mais, que a qualidade dos comentários e os fatos banais, que apareceram publicados na imprensa no início dos anos 1830, iriam conhecer seu momento de glória entre 1880 e $1914 .{ }^{67}$

É então, no momento em que, no campo, se percebe o irremediável declínio da littérature de colportage, que se explica tanto pela repressão policial, quanto pela progressiva conexão entre as diversas regiões da França por uma rede densa de bibliotecas supridas pela rede ferroviária, ${ }^{68}$ que vemos surgir nas grandes cidades milhares de camelôs que parecem herdeiros dos ambulantes de antes. Urbanos e sedentários, enquanto seus antecessores, no século XVIII, tinham se caracterizado, em grande parte, pela itinerância rural. Estes vendedores de "papel", mas também de uma grande variedade de itens, como pentes, descascadores de legumes ou brinquedos para crianças, se parecem, em parte, com os comerciantes de histórias lendárias retratados por Shakespeare, em Um conto no inverno, por meio da figura de Autolycus. ${ }^{69}$ No entanto, eles se diferenciam de seus antecessores devido às transformações da época e, mais particularmente, pelo impacto da reforma da educação universal. Enquanto os comerciantes ambulantes do século XVI concebiam suas baladas para uma clientela recrutada essencialmente naquilo que vimos como uma "multidão" rude e ameaçadora, seus sucessores, desde finais do século XIX, se dirigem aos cidadãos relativamente educados, que supostamente devem sua existência a um sistema democrático onde se pressupõe que o eleitor escolha livremente seus representantes. Ao ler as notícias em seu jornal diário que compra todas as manhãs a preços módicos, ele não poderia ser tentado a comprar a prosa dos camelôs senão com a condição que ela se mostre suficientemente criativa dando a impressão de se ter adquirido esse mesmo suplemento de informação.

É sob efeito do jogo sutil do comentário ligeiro ou hilariante que os escritores de rua e os camelôs que comerciam esses opúsculos irão tentar ganhar a vida na França nos anos 1880 e 1910. Aproveitando-se das grandes crises políticas que abalaram a jovem Terceira República, a campanha revisionista do General Boulanger, o escândalo do canal do Panamá e o affair Dreyfus - três momentos marcantes -, dezenas de poetas e cantores populares, ou aspirantes ao título, de alguma forma colocam esses eventos

67 KALIFA, Dominique. L'encre et le sang. Récits de crime et société à la Belle Epoque. Paris: Fayard, 1995; e KALIFA, Dominique. La culture de masse en France. I. 1860-1930. Paris: La Découverte, 2001. Coleção Repères.

68 DARMON, Jean-Jacques. Le colportage en France sous le second Empire. Paris: Plon, 1972 ; e LYONS, Martyn. Le triomphe du livre. Une histoire sociologique de la lecture en France au XIXe siècle. Paris: Promodis-Editions du cercle de la Librairie, 1987.

69 SHAKESPEARE, W. Le conte d'hiver. In: CEuvres complètes. Paris: Gallimard, 1959, t.2, p.1452-1453. Bibliothèque de la Pléiade, trad. fr. 
nas canções distribuídas nas ruas e vendidas por alguns centavos. ${ }^{70}$ No momento mais intenso da batalha política, que, em 1898, acompanha o pedido de revisão do julgamento do capitão Dreyfus, as canções de ruas, peças humorísticas e outros enterros simbólicos de personagens em relevo e bem vivos eram vendidas às dezenas ou centenas de milhares de exemplares, ou seja, tanto ou mais do que o famoso Eu acuso, de Emile Zola. ${ }^{71}$ Estigmatizada e vista como prova do caráter bestial das multidões, que os criminologistas começam a designar como o inimigo oculto nas sombras das grandes cidades modernas, ${ }^{72}$ a "littérature du ruisseau", como é chamada pelos contemporâneos é, na verdade, uma via de acesso privilegiado às representações das multidões urbanas da época, se tivermos o cuidado de lê-la e estudá-la, juntamente com outros impressos menos nobres.

Complementares à leitura dos acontecimentos banais que abundavam na imprensa popular no período entre o final do século XIX e início do seguinte ${ }^{73}$ esta literatura inquietante para aqueles que a julgavam escandalosa oferecia aos homens da rua uma forma simples, mas eficaz, de decifrar as notícias, de decodificá-la quando era muito complexa, e, dessa forma, reconquistar a confiança que as tensões do momento haviam abalado. Vetor de uma cultura urbana que permite a integração dos migrantes nas cidades, sua procura por sinais, e até mesmo de uma memória, por exemplo aquela dos processos criminais que ensangüentavam a atualidade, esta littérature de colportage merece, então, toda a atenção do pesquisador. É um indicio de uma mudança de época e dos vestígios deixados pelo surgimento de uma forma de cultura em massa, que pressupunha a alfabetização da população e a leitura de minúsculos impressos, como as canções de rua, os convites de enterros simbólicos de políticos ou de seus adversários, ou ainda objetos divertidos, de rodar ou de puxar, próprios para canalizar a violência de um homem irado. Émile Zola foi provavelmente o escritor mais atacado por esta literatura de rua e a vítima simbólica mais martirizada por procuração de seu tempo. ${ }^{74}$ Mas ele era como os homens da Grécia antiga que punham em cena Aristófanes e, ao mesmo tempo, supunham que a leitura desses impressos loucos, e vingativos ou zombeteiros, proporcionava às pessoas da rua uma catarse que lhe permitia esquecer temporariamente a dureza da vida quotidiana.

70 MOLLIER, J.Y. Le camelot et la rue. Para todas as crises e o papel dos camelôs na exasperação das supostas "vítimas" da política.

71 MOLLIER, J.Y. Quando o impresso se transforma em uma arma de combate político: a França dos séculos XV ao XX. In: DUTRA, Eliana de Freitas e MOLLIER, J.Y. (dir.) Politica, nação e edição. Belo Horizonte: Editora UFMG, 2004, p.259-274. NT: Título original, J'accuse.

72 Alphonse Bertillon, Gustave Le Bon, Gabriel de Tarde, Scipio Sighele et Hippolyte Taine publicam suas obras sobre os loucos nesse périodo; cf. BARROWS, Suzanna. Miroirs déformants. Réflexions sur la foule en France au XIXe siècle. Paris: Aubier, 1970.

73 KALIFA, D. L'encre et la sang.

74 MOLLIER, J.Y. Zola et la rue. Les cahiers naturalistes, n.72, p.75-92, 1998. 


\section{História do livro e história das representações}

Ter-se-ia compreendido a história do livro e da edição concebida como tal se não fosse a investigação erudita e reservada de um estreito círculo de pesquisadores ou de membros das academias. Via de acesso privilegiado ao mundo mental dos homens que vivenciaram essa revolução cultural silenciosa, a qual permitiu um verdadeiro acesso de toda a população do país à escola, ao jornal e ao livro, esta permite trazer à história social os elementos preciosos de informação que justificam seu pertencimento a esse ramo da pesquisa, que intitulamos História cultural ou sóciocultural. ${ }^{75}$ Sem retornar aos pressupostos que sustentavam a história das mentalidades, uma espécie de dogma baseado na crença da existência de uma consciência coletiva comum a todos, a história das representações delimita os grupos humanos que ela pretende rastrear a psicologia e cartografar o imaginário. Trabalhando com amostragens mais ou menos amplas, mais numerosas consoante com a emergência da cultura em massa, ela tenta identificar, nas bibliotecas públicas ou privadas, os documentos que possam ser de seu interesse. Examinando cuidadosamente os arquivos mais comuns, aqueles da polícia que recolhe os impressos distribuídos na rua, ou que retira os cartazes considerados ofensivos das paredes das cidades; os da justiça, que muitas vezes condena os pobres, ou os escutam em suas audiências; assim como aqueles dos hospitais, ou hospícios e de todas as instituições que podem ajudar a esclarecer; ela tenta penetrar nos sistemas de crenças que mobilizaram as pessoas no passado.

Comparativa e aberta ao quotidiano, sempre que uma oportunidade apresenta-se, ela não deixa de se debruçar sobre o funcionamento da literatura de rua no mundo árabe-muçulmano, onde ela floresceu nos últimos anos. Ela pode mesmo se deter, como eu fiz em 2004, sobre os poemas de trovadores brasileiros que se referem, eles também, à atualidade política, mesmo a nível internacional, conforme o interesse dos compradores no mercado da Bahia. ${ }^{76}$ Meu comentário sobre o poema de João Sabino Nascimento, um trovador baiano que transformou George W. Bush em anjo do mal e o presidente Lula em seu exato contraponto, um anjo do bem, traz de volta os escritores de rua que, na França do começo do século XX, também tentavam dissipar os receios e oferecer aos seus leitores uma ponte, ou uma chave, que poderia ajudá-los a atravessar um período difícil de turbulências e agitações. Embora não convenha exagerar as semelhanças e, ao contrário, é necessário especificar as condições exatas da produção, divulgação e recepção dos impressos de rua, a história do livro e da edição

75 MARTIN, Laurent e VENAYRE, Sylvain. (dir.) L'histoire culturelle du contemporain. Paris: Nouveau Monde Editions, 2005; e POIRRIER, Philippe. (dir.) L'histoire culturelle, un "tournant mondial" dans l'historiographie. Dijon: Editions universitaires, 2008.

76 MOLLIER, J.Y. Le camelot et la rue, p.310-314. 
alarga sua abordagem quando ela aceita expandir o objeto de suas investigações a todos os impressos que irrigam o tecido dos vasos sanguíneos de uma determinada sociedade. Afinal, como já escreveu com humor um poeta da Revolução Francesa, muitos textos terminaram em papel reciclado sobre a barraca de um vendedor de peixe ou de um açougueiro. ${ }^{77} \mathrm{E}$, não podemos ignorar esses diversos usos do papel mais nobre, se pretendemos uma abordagem mais próxima às representações das populações sobre as quais trabalhamos. Apenas para terminar, entendida como a história humana, a história da impressão não tem outra justificação, como em qualquer investigação que seja científica, que a de tentar mostrar como viviam os homens e as mulheres do passado, dos mais humildes aos mais educados. Abordar os primeiros é sempre e infinitamente uma tarefa mais complexa e confusa de que os segundos.

77 BAECQUE, Antoine de. Les éclats du rire. La culture des rieurs au XVIIle siècle. Paris: Calmann-Lévy, 2000. 